\title{
EBV-Positive Plasmablastic Lymphoma Mimicking Reactive Lymphadenopathy versus Recurrent Hodgkin Lymphoma Following Chemotherapy for Stage II Classical Hodgkin Lymphoma
}

Cyrus Parsa ${ }^{1 *}$, Robert Orlando ${ }^{2}$, Ravin Rupani ${ }^{3}$, Jin Guo ${ }^{4}$ and Dylan Denault ${ }^{5}$

${ }^{1}$ Department of Pathology, Western University of Health Sciences, Pomona, California and Director of Laboratories, Beverly Hospital, Montebello, California

${ }^{2}$ Director of Laboratories, Beverly Hospital, Montebello, California

${ }^{3}$ Western University of Health Sciences and Associate Pathologist, Beverly Hospital, Montebello, California

${ }^{4}$ Clinical Oncologist, Beverly Hospital, Montebello, California

${ }^{5}$ Western University of Health Sciences, California

"Corresponding author: Cyrus Parsa, Chair, Department of Pathology, Western University of Health Sciences, Pomona, California and Director of Laboratories, Beverly Hospital, Montebello, California, Tel: 323-889-2414, Fax: 323-889-2406; E-mail: cparsa@westernu.edu

Received Date: March 5, 2018; Accepted Date: March 23, 2018; Published Date: March 28, 2018

Copyright: (c) 2018 Parsa C, et al. This is an open-access article distributed under the terms of the Creative Commons Attribution License, which permits unrestricted use, distribution, and reproduction in any medium, provided the original author and source are credited.

\begin{abstract}
Plasmablastic lymphoma $(\mathrm{PBL})$ is a rare malignancy derived from activated $B$ cells within the germinal center in the process of transformation to plasma cells. The neoplasm is an aggressive and diagnostically challenging type of lymphoma. It is most commonly associated with HIV infection, but may also occur in other immunodeficiencies, elderly patients, and immunocompetent individuals. In this paper, we discuss the clinic pathologic features of a 93year-old male, possibly the oldest reported case, with PBL, status post-chemotherapy for Hodgkin lymphoma, initially suspected of representing reactive, possibly infectious, lymphadenopathy versus recurrent Hodgkin lymphoma.
\end{abstract}

Keywords: Plasmablastic lymphoma; Hodgkin lymphoma; EpsteinBarr virus; IHC

\section{Introduction}

World Health Organization (WHO) has introduced a long list of new diffuse large B-cell lymphoma (DLBCL) entities and subtypes particularly related to specific sites and the association with virus (EBV and/or HHV8); these virus have frequent morphologic and immunophenotypic characteristics of terminal (Plasmablastic) B-cell differentiation [1]. Plasmablastic lymphoma was first described in 1997, predominantly reported in the oral cavity of HIV-positive males [2]. Since then PBL cases have been identified in HIV-negative, iatrogenic immunosuppressed and immunocompetent patients, as well as in association with other malignancies [3-6]. It has been identified in many body sites including but not limited to: gastrointestinal (oral cavity to rectum), lymph nodes, skin and bone marrow [2,7]. The diagnosis can be difficult because of the varied clinical presentation, and lack of expression of pan-B-cell and CD45 antigens on the neoplastic cells [5].

\section{Case Report}

A 93-year-old male was first diagnosed with stage IIB classical Hodgkin lymphoma four years earlier and subsequently treated with [6] cycles of ABVD (Doxorubicin + Bleomycin + Vinblastine + Dacarbazine). He currently presented for follow-up Hodgkin lymphoma evaluation complaining of mild fatigue. Past medical history included: cancer of prostate, diagnosed approximately 15 years earlier, for which he had received radiation therapy; thrombocytopenia due to idiopathic thrombocytopenic purpura (ITP); diabetes mellitus; hypercholesterolemia; and hypertension.

On his current presentation, the patient's hemoglobin was 6.2 $\mathrm{mg} / \mathrm{dL}$, prompting transfusions with two units of packed red blood cells. He had a recent bone marrow biopsy which showed no evidence of malignancy with normal flow cytometry as well as cytogenetics. Since the diagnosis of Hodgkin lymphoma, the patient had multiple CT scans. A recent PET CT showed extensive hyper metabolic activity which, however, was fairly stable from the prior PET scan done two months earlier. Given the persistent, but not increasing, activity the findings were clinically suspicious for possibly chronic inflammatory condition or infectious etiology rather than lymphoma, which would generally increase in size. An inguinal lymph node biopsy was recommended for pathological diagnosis.

A surgically excised "right groin" lymph node, $3.5 \times 3.0 \times 1.5 \mathrm{~cm}$ in greatest dimensions, was submitted for flow cytometry and histopathological diagnostic consultation. Flow cytometry analysis of the lymph node showed "no flow immunophenotypic evidence of a lymph proliferative disorder" The cut surface of the excised lymph node was pale $\tan$ to tan-white and homogeneous. The histologic sections showed an extensively fibrotic lymphoid tissue, variably infiltrated by irregular sheets of cells with abundant pale eosinophilic cytoplasm (Figure 1), large vesicular nuclei, prominent nucleoli, and occasional atypical mitoses (Figure 2). The surrounding lymphoid tissue consisted of small reactive-appearing lymphocytes. On immunohistochemistry, the large atypical cells were diffusely positive for IRF-4/MUM1 (Figure 3) and CD138 (Figure 4) with kappa/lamda studies showing strong lambda light chain restriction, positive for Epstein-Barr encoding region (EBER) by in situ hybridization (Figure $5)$. 
Citation: Parsa C, Orlando R, Rupani R, Guo J, Denault D (2018) EBV-Positive Plasmablastic Lymphoma Mimicking Reactive

Lymphadenopathy versus Recurrent Hodgkin Lymphoma Following Chemotherapy for Stage II Classical Hodgkin Lymphoma. J Tumor Res \& Reports 3: 117.

Page 2 of 4

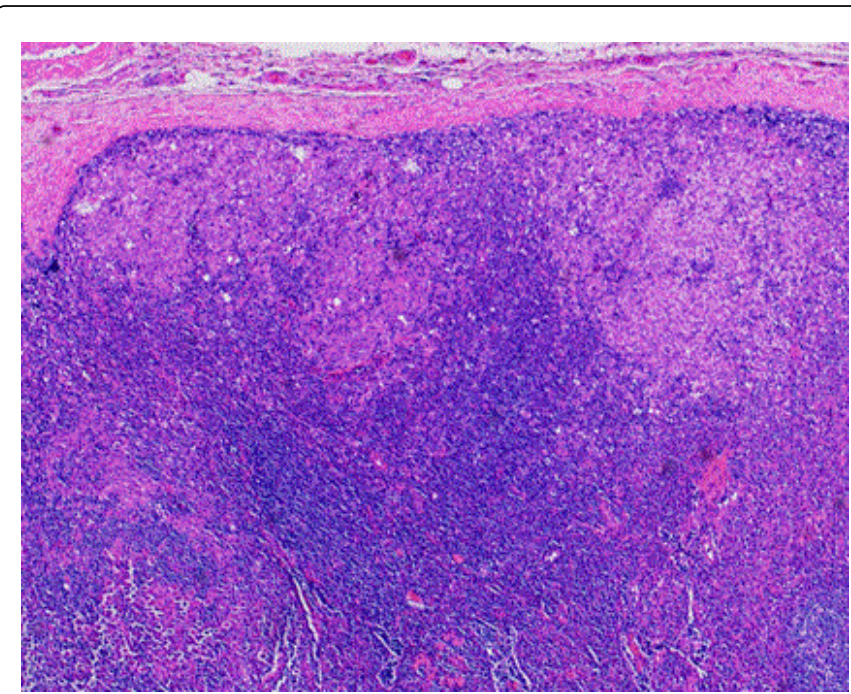

Figure 1: Sections of the lymph node show effacement of nodal architecture, variably infiltrated by sheets and clusters of cells with abundant pale eosinophilic cytoplasm.

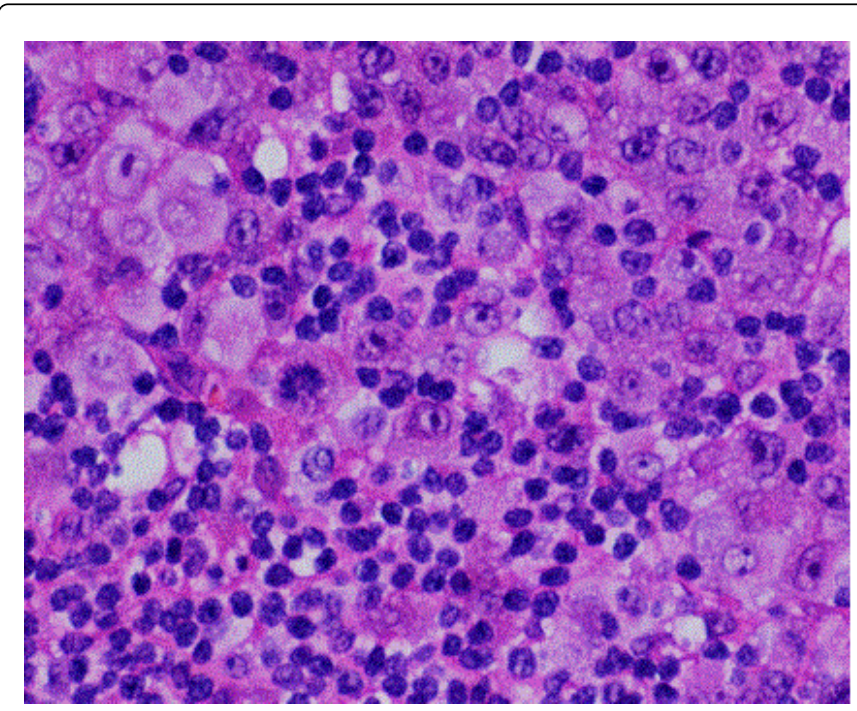

Figure 2: High-power view show atypical cells with large vesicular nuclei with prominent nucleoli. An atypical mitosis is discernible, just left of mid field in this image.

Immunostain for the proliferative index, Ki-67, was estimated at $70 \%$ (Figure 6). The atypical cells were variably positive for CD30 (usually in single cells and not in aggregates). CD20 showed very weak and variable staining, while CD3, CD5, CD10, CD23, CD43, BCL2, BCL6, pan-cytokeratin, CD79A, PAX5, and CD15 were all negative on the large atypical cells. The florescent in situ hybridization (FISH) study for MYC (8q24) was negative. Based on the immunohistochemical stains, flow cytometry analysis, FISH studies, and cell morphology the patient was diagnosed with EBV-positive plasmablastic lymphoma (Figures 1-6).

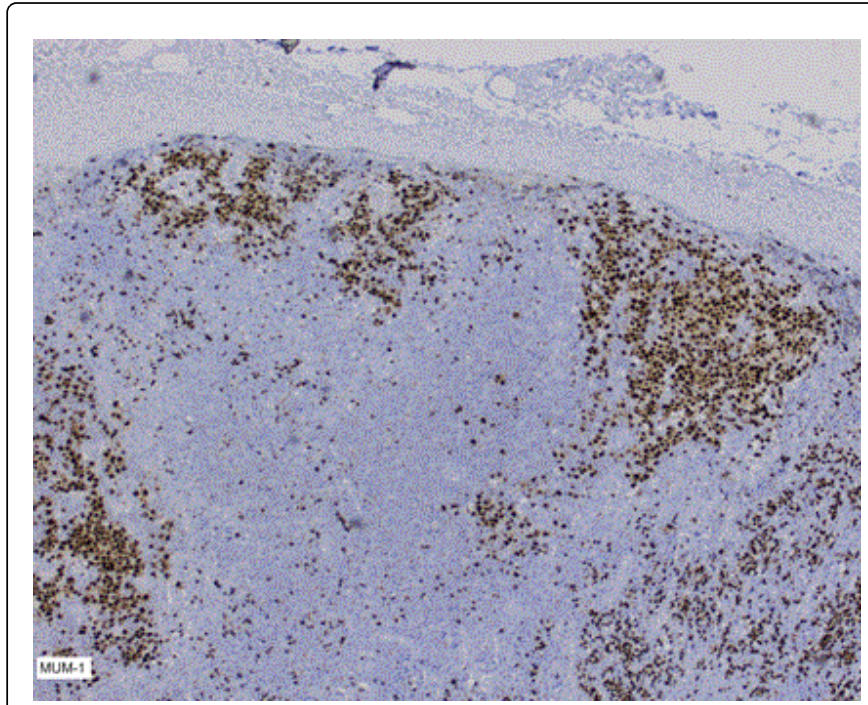

Figure 3: The neoplastic cells are diffusely and strongly positive for MUM-1, a marker for post germinal center or activated B-like DLBCL.

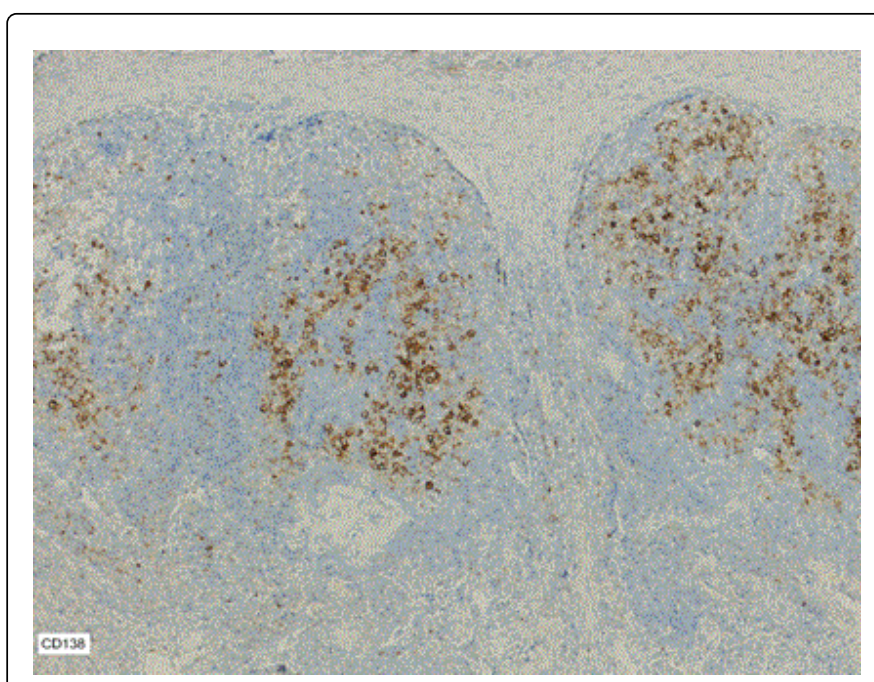

Figure 4: The neoplastic cells are conspicuously positive for the plasma cell marker, CD138.

\section{Discussion}

Plasmablastic lymphoma (PBL) is a rare neoplasm with morphologic and immunophenotypic characteristics that overlap with aggressive large B-cell lymphomas and with plasma cell neoplasms5. The 2008 WHO lists PBL as a rare subtype of diffuse large B-cell lymphoma.

It is considered of germinal center origin, derived from a plasma cell precursor. Differentiation of a B-cell into a plasma cell relies on the successful completion of apoptosis in many cells in order to prevent the survival of self-reactive cells generated in the process of somatic hyper mutation [3]. 
Citation: Parsa C, Orlando R, Rupani R, Guo J, Denault D (2018) EBV-Positive Plasmablastic Lymphoma Mimicking Reactive Lymphadenopathy versus Recurrent Hodgkin Lymphoma Following Chemotherapy for Stage II Classical Hodgkin Lymphoma. J Tumor Res \& Reports 3: 117.

Page 3 of 4

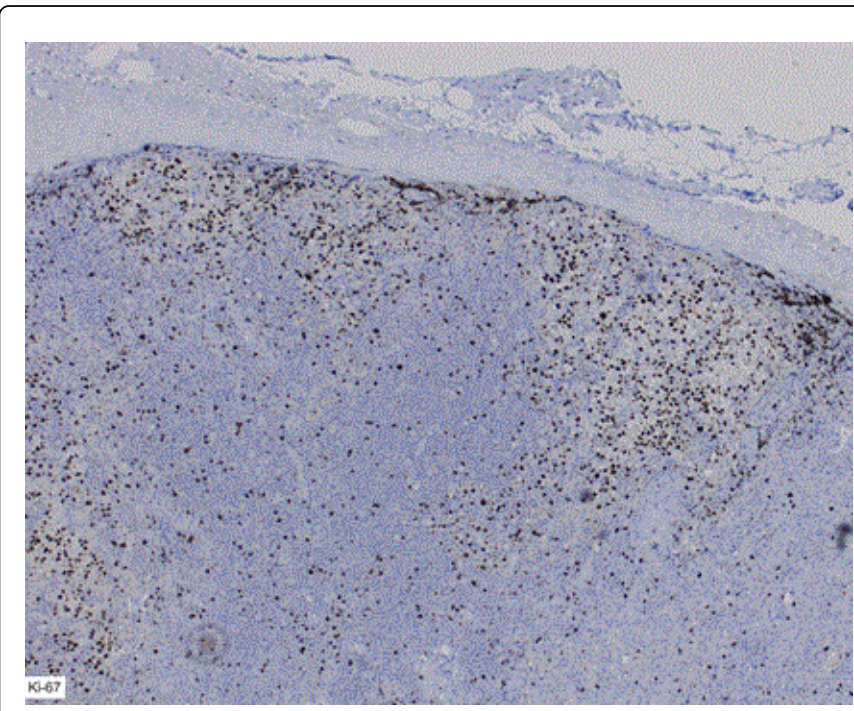

Figure 5: Immunostain Ki-67, a marker of cell proliferation, is high at $70 \%$ in the triangular-shaped plasmablastic regions of the lymph node.

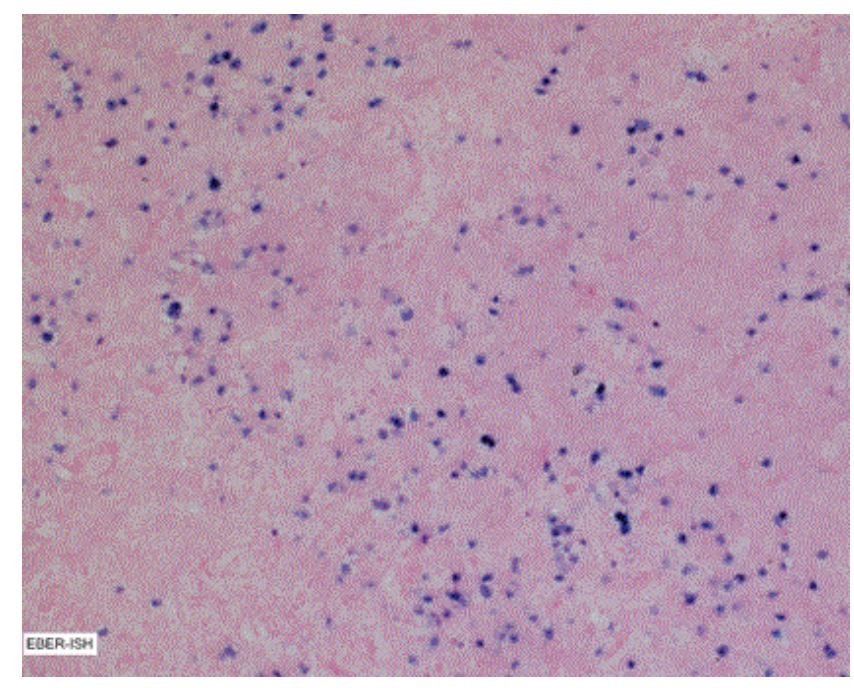

Figure 6: Scattered cells stain positive for Epstein-Barr encoding region (EBER) by in situ hybridization (ISH).

In PBL there is an aversion of B-cell apoptosis allowing for cells to gain the neoplastic trait of prolonged survival. In PBL that is positive for EBER (EBV-encoded RNA, a marker commonly used to determine EBV expression), EBV is believed to be the cause of apoptosis aversion by interrupting apoptotic pathways regulated by NF-kB and BAX [3].In order for these cells to proliferate unchecked, other mutations are necessary. Ki-67, an Immunostain marker of proliferative index, can be used to elucidate the extent to which PBL can undergo pathologic proliferation.

The diagnosis of plasmablastic lymphoma is challenging since that neoplasm is negative for the usual B-cell markers and there are other disorders that may display clinicopathologic features similar to PBL and must be differentiated from this neoplasm [8]. These disorders include, but are not limited to, anaplastic large cell lymphoma kinase (ALK) positive diffuse large B-cell lymphoma (DLBCL), primary effusion lymphoma (PEL), and large B-cell lymphoma associated with human herpes virus [8] (HHV-8) infection. Some clinical, genetic, and immunochemical differences often exist that help distinguish PBL from each of these B-cell lymphomas with plasmablastic features, some of these differences are discussed below.

Primary Effusion lymphoma may be negative for CD138, exists in the presence of multicentric Castle man disease, and its pathogenesis is often associated with HHV-8 and not with EBV. Anaplastic lymphoma kinase positive diffuse large B-cell lymphoma is typically a nodal mass, not associated with HIV, variable positive for CD138, and positive for CD4 and CD45.14 The most characteristic feature of ALK+ DLBCL is the expression of ALK, usually resulting from at $[2,9]$ (q23;q23), an ALK-CLTC fusion product [6,8]. In contrast to these neoplasms, PBL is more often extra nodal than nodal, is associated with HIV infection in about 70\% of cases, expresses CD138, does not typically express CD4, CD45, or ALK [8-12]. Other plasma cell markers that may be expressed by PBL may include XBP1s, PRDm1/ BLIMP1, and CD138/syndecan-1 [12,13].

Although PBL is known to occur in patients with history of other types of lymphoma [14-16] including Hodgkin lymphoma[13,16] the pathogenesis of its development in these patients is generally considered to be related to immunosuppressive (chemotherapy-related or iatrogenic) rather than Richter type high-grade lymphoma transformation [17-19]. PBL usually involves the oral mucosa of immune deficient patients, but can also occur in approximately $35 \%$ of immunocompetent and elderly individuals [5,17]. PBL is now known to occur in a variety of body sites, and in association with certain other disorders and treatment settings. The disease has a higher prevalence in the male population.

The prognosis of PBL is poor, with an overall median survival of 8 months [18]. Variety of treatments has been proposed for PBL [19] Cyclophosphamide, doxorubicin, vincristine, and prednisone commonly used for DLBCL is generally considered inadequate for PBL3. Because PBL displays a degree of plasma-cystic differentiation [20-25], agents used in the treatment of plasma cell myeloma (e.g., bortezomib and lenalidomide) have been used with some success [8-11]. Rituximab has been recommended to be added to the chemotherapy regiment in uncommon PBL cases that express CD20 [10]. Autologous stem cell transplantation in the case of relapse and refractory disease have also been tried. Although rare, and diagnostically challenging, it is essential to include PBL in the differential diagnosis of lymphadenopathy in any patient with past medical history of lymphoma on chemotherapy, especially considering PBL's association with poor prognosis [26,27].

\section{Acknowledgment}

We are grateful to Dr. Lawrence $M$ Weiss at Neo-Genomics Laboratories for his expertise in diagnostic consultation on this case.

\section{Conflict of Interest}

We declare absence of conflict of interest in this presentation. 
Citation: Parsa C, Orlando R, Rupani R, Guo J, Denault D (2018) EBV-Positive Plasmablastic Lymphoma Mimicking Reactive Lymphadenopathy versus Recurrent Hodgkin Lymphoma Following Chemotherapy for Stage II Classical Hodgkin Lymphoma. J Tumor Res \& Reports 3: 117.

Page 4 of 4

\section{References}

1. Stein H, Harris NL, Campo E, Swerdlow SH, Thiele J, et al. (2008) WHO Classification of Tumors of Hematopoietic and Lymphoid Tissues. IARC Press: 256-257.

2. Delecluse HJ, Anagnostopoulos I, Dallenbach F, Hummel M, Marafioti T, et al. (1997) Plasmablastic lymphomas of the oral cavity: a new entity associated with the human immunodeficiency virus infection. Blood 89: 1413-1420.

3. Castillo JJ, Bibas M, Miranda R (2015) The Biology and treatment of Plasmablastic lymphoma. Blood. 2015: 2323-2330.

4. Min L, Bailong L, Bin L, Qiang W, Lijuan D, et al. (2015) Human immunodeficiency virus-negative plasmablastic lymphoma: A comprehensive analysis of 114 cases. Oncol Rep 33: 1615-1620.

5. Harmon CM, Smith LB (2016) Plasmablastic lymphoma, and review of clinicopathologic features and differential diagnoses. Arch Pathol Lab Med 140: 1074-1078.

6. Castillo JJ, Winer ES, Stachurski D, Perez K, Jabbour M, et al. (2011) HIVnegative plasmablastic lymphoma: not in the mouth. Clin Lymphoma Myeloma Leuk 11: 185-189.

7. Parsa C, Orlando R (2017) EBV positive plasmablastic lymphoma presenting as a rectal mass in an HIV-positive patient. The Medical Journal of Southern California Clinicians 11: 4-6.

8. Hsi ED, Lorsbach RB, Fend F, Dogan A (2011) Plasmablastic lymphoma and related disorders. Am J Clin Pathol 136:183-194.

9. Liu JJ, Zhang L, Ayala E, Field T, Ochoa-Bayona J, et al. (2011) Human immunodeficiency virus (HIV)-negative plasmablastic lymphoma: a single institutional experience and literature review. Leuk Res 35:1571-1577.

10. Bennett MH, MacLennan KA, Hudson VG, Hudson BV (1991) NonHodgkin's lymphoma arising in patients treated for Hodgkin's disease in the BNLI: a 20-year experience. British National Lymphoma Investigation. Ann Oncol pp 83-92.

11. Martinez D, Valera A, Perez N, Villegas LFS, Carla Sole, et al. (2013) Plasmablastic Tranformation of low-grade B-cell Lymphomas Report on 6 Cases. Am J Sug Path. 37: 272-281.

12. Ok CY, Papathomas TG, Medeiros LJ, Young KH (2013) EBV-positive diffuse large B-cell lymphoma of the elderly. Blood $122: 328-340$.

13. Yan M, Dong Z, Zhao F, Chauncey T, Limayo DD, et al. (2014) CD20positive plasmablastic lymphoma with excellent response to bortezomib combined with rituximab. Eur J Haematol. 93: 77-80.

14. Nicholson M, Kavuri A, Ustun C, Crawford J, Kapoor NA, et al. (2008) Plasmablastic lymphoma: cytologic findings in 5 cases with unusual presentation. Cancer Cytopathology 114: 333-341.

15. Robak T, Urbanska-Rys H, Strzelecka B, Krykowski B, Bartkowiak j, et al. (2001) Plasmablastic lymphoma in a patient with chronic lymphocytic leukemia heavily pretreated with cladribine (2-CdA): an unusual variant of Richter's syndrome. Eur J Haematol 67: 322-327.
16. Vega F, Chang CC, Medeiros LJ, Udden MM, Cho-Vega JH, et al. (2004) Plasmablastic lymphomas and plasmablastic plasma cell myelomas have nearly identical immunophenotypic profiles. Mod. Pathol. 18: 806-815.

17. Liu F, Asano N, Tatematsu A, Oyama T, Kitamura K, et al. (2012) Plasmablastic lymphoma of the elderly: a clinicopathological comparison with age-related Epstein-Barr virus-associated B cell lymphoproliferative disorder. Histopathology. 61: 1183-1197.

18. Al Malki MM, Casillo JJ, Sloan JM, Re A (2014) Hematopoietic cell transplantation for plasmablastic lymphoma: a review biology. Blood Marrow Transplant 20: 1877-1884.

19. Ouansafi I, He B, Fraser C, Nie K, Mathew S, et al. (2010) Transformation of follicular lymphoma to plasmablastic lymphoma with c-myc gene rearrangement. Am J Clin Pathol. 134: 972-981.

20. Foo WC, Huang Q, Sebastian S, Hutchinson BC, BurchetteJ, et al. (2010) Concurrent classical Hodgkin lymphoma and plasmablastic lymphoma in a patient with chronic lymphocytic leukemia/small lymphocytic lymphoma treated with fludarabine: A dimorphic presentation of iatrogenic immunodeficiency-associated lymph proliferative disorder with evidence suggestive of multiclonal transformability of B cells by Epstein-Barr virus. Hum Pathol 41:1802-1808.

21. Morscio J, Diericks D, Nijs J, Verhoef G, Bittoun E, et al. (2014) clinicopathologic comparison of patient's: Single centers series of 25 cases and meta-analysis of 227 reported cases. Am J Surg Pathol 38: 875-886.

22. Dasanu CA, Bauer F, Codreanu I, Padmanabhan P, Rampurwala M (2013) Plasmablastic haemato-lymphoid neoplasm with a complex genetic signature of Burkitt lymphoma responding to bortezomib. Hematol Oncol 3: 164-166.

23. Bibas M, Grisetti S, Alba L, Picchi G, Del Nonno F, et al. (2010) Patient with HIV-associated plasmablastic lymphoma responding to bortezomib alone and in combination with dexamethasone, gemcitabine, oxaliplatin, cytarabine, and pegfilgrastim chemotherapy and lenalidomide alone. J Clin Oncol 28: 704-708.

24. Castillo JJ, Reagan JL, Sikov WM, Winer ES (2015) Bortezomib in combination with infusional dose-adjusted EPOCH for the treatment of plasmablastic lymphoma. Br J Haematol. 169:352-355.

25. Castillo JJ, Beltran BE, Miranda RN, Paydas S, Winer ES, et al. (2011) Epstein-barr virus-positive diffuse large B-cell lymphoma of the elderly: what we know so far. Oncologist $16: 87-96$.

26. Montes-Moreno S, Gonzalez-Medina AR, Rodriguez-Pinilla SM, Maestre L Sanchez-Verde L, et al. (2010) Aggressive large B-cell lymphoma with plasma cell differentiation: immunohistochemical characterization of plasmablastic lymphoma and diffuse large B-cell lymphoma with partial plasmablastic phenotype. Haematologica 95: 1342-1349.

27. Wu JZ, Min K, Fan L, Wang L, Xu J, et al. (2014) Plasmablastic lymphoma following combination treatment with fludarabine and rituximab for nongastric mucosa-associated lymphoid tissue lymphoma: a case report and review of literature. Int J Clin Exp Pathol 7: 4400-4407. 